\title{
PET reveals occipitotemporal pathway activation during elementary form perception in humans
}

\author{
LORI L. BEASON-HELD,${ }^{1}$ KEITH P. PURPURA, ${ }^{2}$ JOHN W. VAN METER, ${ }^{1}$ NINA P. AZARI, ${ }^{1}$ \\ DAVID J. MANGOT, ${ }^{1}$ LANCE M. OPTICAN,${ }^{3}$ MARC J. MENTIS, ${ }^{1}$ GENE E. ALEXANDER, ${ }^{1}$ \\ CHERYL L. GRADY, ${ }^{1}$ BARRY HORWITZ, ${ }^{1}$ STANLEY I. RAPOPORT, ${ }^{1}$ AND MARK B. SCHAPIRO ${ }^{1}$ \\ ${ }^{1}$ Laboratory of Neurosciences, National Institute on Aging, National Institutes of Health, Bethesda \\ ${ }^{2}$ Department of Neurology and Neuroscience, Cornell University Medical College, New York \\ ${ }^{3}$ Section on Neural Modeling, National Eye Institute, National Institutes of Health, Bethesda
}

(Received July 30, 1997; ACCEPTED November 14, 1997)

\begin{abstract}
To define brain regions involved in feature extraction or elementary form perception, regional cerebral blood flow $(\mathrm{rCBF})$ was measured using positron emission tomography (PET) in subjects viewing two classes of achromatic textures. Textures composed of local features (e.g. extended contours and rectangular blocks) produced activation or increased $\mathrm{rCBF}$ along the occipitotemporal pathway relative to textures with the same mean luminance, contrast, and spatial-frequency content but lacking organized form elements or local features. Significant activation was observed in striate, extrastriate, lingual, and fusiform cortices as well as the hippocampus and brain stem. On a scan-by-scan basis, increases in rCBF shifted from the occipitotemporal visual cortices to medial temporal (hippocampus) and frontal lobes with increased exposure to only those textures containing local features. These results suggest that local feature extraction occurs throughout the occipitotemporal (ventral) pathway during extended exposure to visually salient stimuli, and may indicate the presence of similar receptive-field mechanisms in both occipital and temporal visual areas of the human brain.
\end{abstract}

Keywords: Positron emission tomography, Visual, Striate, Extrastriate, Hippocampus, Frontal lobe

\section{Introduction}

The primate visual system is believed to be organized into dorsal and ventral processing streams (Kleist, 1934; Ungerleider \& Mishkin, 1982). Electrophysiological studies in awake monkeys and cognitive studies in humans and monkeys with selective cortical lesions suggest that the occipitotemporal (ventral) pathway is dedicated to visual form analysis and pattern recognition (Gaffan et al., 1986; Doyon \& Milner, 1991; Pigott \& Milner, 1993; Logothetis et al., 1995). Brain-imaging studies in humans also support the role of the ventral pathway in form and pattern perception. Activation of the occipitotemporal pathway has been reported during performance of tasks involving attention to shape (Corbetta et al., 1990), and tasks associated with objects (Kosslyn et al., 1994; Schacter et al., 1995), faces (Haxby et al., 1991; Horwitz et al., 1992; Puce et al., 1995), and textures (Malach et al., 1995; Roland \& Gulyas, 1995; Puce et al., 1996). Functional imaging further suggests hemispheric specialization of the ventral stream, with a left lateralization for visual word processing (Peterson et al., 1990; Kapur et al., 1996; Menard et al., 1996; Gur et al., 1997), and a right lateralization for the perception of form such as illusory

Correspondence and reprint requests to: Lori Beason-Held, NIA, NIH, Bldg. 10, Rm. 6C414, 9000 Rockville Pike, Bethesda, MD 20892, USA. contours (Hirsch et al., 1995) and nonsense letter strings and false fonts (Petersen et al., 1990; reviewed in Posner \& Raichle, 1994).

In the monkey, this ventral pathway is identified with more foveal and parafoveal regions of visual areas V1-V4 (Gattass et al., 1988; Baizer et al., 1991) and with the inferiotemporal, entorhinal, and perirhinal cortices and hippocampus (see Suzuki, 1996). Several characteristics of the receptive fields in these cortical regions are known from single-unit studies. First, the central visual-field specialization is maintained throughout the pathway as the receptive fields increase in size by orders of magnitude in the inferiotemporal cortex (Gattass et al., 1988). Second, visual attributes which most effectively stimulate these receptive fields become increasingly complex in more rostral regions (see Logothetis \& Sheinberg, 1996). Third, while behavioral set and task performance influence evoked neural responses in early visual areas (Wurtz \& Mohler, 1976; Luck et al., 1997), the largest effects occur in cortical regions rostral to areas V1-V3 (Motter, 1993; Desimone \& Duncan, 1995).

Although evidence supporting the role of the occipitotemporal pathway in form analysis is considerable, it is not known if similar receptive-field mechanisms, such as those that group local features together and incorporate information from larger and larger regions of the visual field, are present throughout all cortical areas of this pathway. Modeling studies (Grossberg et al., 1997) suggest that a neural circuit involving feed-forward integration from the 
lateral geniculate nucleus (LGN), and local feature extraction followed by long-range cooperative feature integration in striate cortex (V1) is replicated at a larger spatial scale in V2, the first extrastriate visual area. Perhaps this type of circuit is replicated throughout the occipitotemporal pathway, with each region connected via feed-forward and feed-back circuits to adjacent anterior and posterior regions, respectively. Such an extended network would be useful for the extraction of regularity and continuity independent of spatial scale. These operations could in turn facilitate figure/ ground segregation and pattern recognition.

To determine regional participation in local feature extraction, we performed an experiment involving the ability to perceive structural organization within visual images. While the process of feature extraction occurs when one examines complex visual scenes or images such as faces or objects, this study is concerned exclusively with the regional specificity of elementary form perception. Here, two classes of achromatic textures were shown to subjects undergoing a series of positron emission tomography (PET) scans where regional cerebral blood flow ( $\mathrm{rCBF}$ ) was used as an index of synaptic activity (see Jueptner \& Weiller, 1995). In the "Even" textures (Julesz et al., 1978; Victor \& Zemon, 1985; Victor, 1985), black and white pixels (i.e. the smallest texture elements) were organized into elongated contours and rectangular shapes. "Random" textures, in contrast, exhibited black and white pixels of the same size but these pixels were randomly arranged. Due to statistical constraints (see Fig. 1), the contiguous regions of white or black were the same size, on average, in the Even and Random textures, yet in Even textures these regions were organized into regular rectangular shapes. As a consequence, both texture classes shared the same spatial-frequency content (i.e. spatial power spectra) but differed in spatial-phase spectra. Thus, receptive-field mechanisms which produce differential responses to Even and Random textures can do so based only on differences between the two classes of textures (i.e. the organization of the visual elements within the images).

In this experiment, each subject underwent a series of eight PET scans. Four scans were collected during Random texture viewing and four while viewing Even textures (Fig. 1). The data were analyzed to assess the overall brain activation pattern resulting from Even texture stimulation relative to the baseline Random
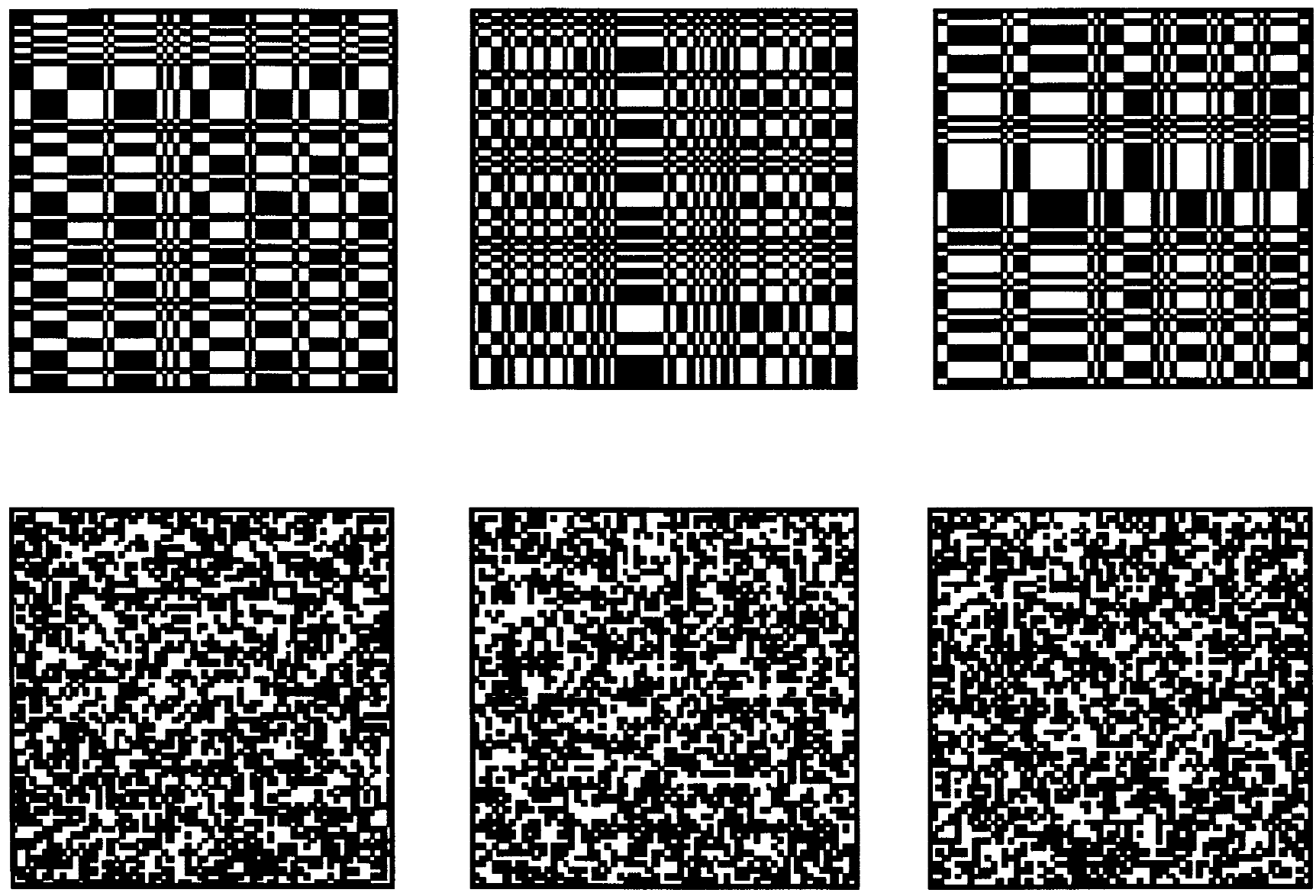

Fig. 1. Examples of Even (top row) and Random (bottom row) textures. Even textures are generated by a simple two-dimensional recursion rule from sets of randomly chosen values for the textures' initial rows and columns. If pixel color (black or white) is denoted in the $i$ th row and $j$ th column of the two-dimensional array by $a i, j=1$, and the colors of pixels in the initial row and column ( $a 0, j$ and $a i, 0)$ are randomly assigned values of +1 or -1 , a recursion rule determines the assignment of the interior pixels of the texture from those previously assigned. The interior pixels of an Even texture are assigned by the rule $a i+1, j+1=a i, j+1 \times a i+1, j \times$ $a i, j$. Stimuli were produced on a CRT at a $60 \mathrm{~Hz}$ noninterlaced frame rate by a Number Nine graphics card within a 486 PC. 
stimulation, and to assess the effects of repeated stimulation as each subject saw many examples of Even/Random textures four times during the scanning session.

\section{Methods}

\section{Subjects}

rCBF was measured in eight healthy young adults (four women, four men; ages 20-37 years). Following full explanation of purpose, procedures, and risks of the study, informed consent was obtained from each subject. Subjects were medically screened to exclude brain or systemic diseases that might affect brain function, including visual-field deficits and abnormal acuity. Those with suboptimal visual acuity wore corrective lenses during scanning.

\section{Visual stimulation}

Each subject underwent a series of eight PET scans using radiolabeled water $\left(\mathrm{H}_{2}{ }^{15} \mathrm{O}\right)$. The subjects were given no prior exposure to the stimuli before beginning the scans nor any instructions other than to keep their gaze centered on the visual display. The texture display subtended $22.5 \mathrm{deg} \times 28.3 \mathrm{deg}$ of visual angle. The smallest pixel (region of black or white) in the textures subtended $0.16 \times 0.16$ deg of visual angle.

Four scans were collected during Random texture viewing and four while viewing Even textures (Fig. 1). Scans were administered in an alternating fashion, with each pair of Random/Even scans counterbalanced across subjects to control for effects of presentation order. Novel texture examples were used throughout the scanning session. Textures were continuously shown every $0.5 \mathrm{~s}$, beginning approximately $45 \mathrm{~s}$ prior to scanning and continuing throughout the 4-min scan. Scans were conducted every $12 \mathrm{~min}$.

\section{PET scanning}

PET procedures were performed on a Scanditronix PC2048-15B tomograph (Uppsala, Sweden) with a reconstruction resolution of $6.5 \mathrm{~mm}$ in both transverse and axial planes. Catheters were placed in a radial artery to obtain arterial blood samples and in an anticubital vein of the opposite arm for isotope injection. $37.5 \mathrm{mCi}$ of $\mathrm{H}_{2}{ }^{15} \mathrm{O}$ were injected intravenously per scan. Scanning began when the brain radioactive count rate reached a threshold level and continued for $4 \mathrm{~min}$. Arterial blood radioactivity was determined continuously using an automated blood counter. The arterial timeactivity curve and scan data were used for image reconstruction with a rapid least-squares algorithm (Holden et al., 1981; Carson et al., 1987).

Scans were interpolated from the original 15 to 43 slices (Woods et al., 1992) and were registered and spatially normalized (Friston et al., 1991) to fit the image into stereotaxic space of Talairach and Tournoux (1988). Images were smoothed using a Gaussian filter with a full width at half maximum of $20 \mathrm{~mm} \times 20 \mathrm{~mm} \times 12 \mathrm{~mm}$. For each subject, pixel rCBF values from a given scan were normalized to the global mean flow of that scan and then scaled to the grand global mean flow across all scans using the ratio-adjusted method (Fox et al., 1988).

\section{Data analysis}

The image data were analyzed using statistical parametric mapping (SPM4.0) (Frackowiak \& Friston, 1994), where voxel by voxel comparisons determined significant changes in rCBF during Even stimulation relative to baseline Random stimulation $(P \leq 0.01)$. To determine the overall activation pattern resulting from Even stimulation, data from all Even scans were analyzed relative to all Random scans. Because subjects underwent four scans per stimulation condition, two within-condition comparisons (i.e. last scan $v s$. first scan for both Even and Random conditions) were performed to assess the effects of repeated stimulation, followed by four post-hoc pair-wise comparisons (i.e. first Even vs. first Random, second Even vs. second Random, etc.). To control for multiple comparisons, cluster analyses were performed to identify voxels that exceeded a $Z$-score of $2.36(P \leq 0.01)$ and to determine the significance of each cluster of voxels based on spatial extent $(P \leq$ 0.05) (Friston et al., 1994).

\section{Results}

Activation results are shown in Fig. 2. The local maxima are shown in Table 1. Regional activations are described in terms of Brodmann areas (BA) from the atlas of Talairach and Tournoux (1988).

Relative to Random texture stimulation, the overall pattern of cerebral activation during Even stimulation involved both occipital and temporal regions. This activation was lateralized predominately to the right hemisphere. Increases in right hemisphere $\mathrm{rCBF}$ were observed in middle occipital (BA 19), lingual (BA 18/19), and fusiform gyri (BA 19/37) with additional areas of activation in the hippocampus, parahippocampal gyrus (BA 30/35), middle temporal gyrus (BA 19/39), and brain stem. Significant left hemisphere increases in $\mathrm{rCBF}$ were observed in primary visual cortex (BA 17), middle occipital (BA 18/19), lingual (BA 18/19), and fusiform gyri (BA 19).

In terms of the effect of repeated stimulation, rCBF during the Even condition significantly varied as a function of presentation order. Relative to the first Even scan, the last Even scan showed large regions of significant $\mathrm{rCBF}$ increases in the hippocampal region (hippocampal formation and associated ventromedial temporal cortex) [Talairach Coordinate: 18 -30 -4 ], thalamus [14 22 0] and middle frontal gyrus (BA 10) [24 36 12] primarily in the right hemisphere. $\mathrm{rCBF}$ during the last relative to the first Random scan showed only a small area of increase in the superior-most aspect of the middle frontal gyrus (BA 9) [42 0 36] of the right hemisphere. Pair-wise comparisons (i.e. first Even vs. first Random, etc.) demonstrated significant exposure-dependent rCBF increases. During the first Even presentation, increased rCBF was observed in primary visual cortex (BA 17) and middle occipital gyrus (BA 19) of the left hemisphere, and lingual (BA 18) and middle occipital gyri (BA 18/ 19) of the right hemisphere. During the second presentation of Even textures, increased $\mathrm{rCBF}$ was observed in primary visual cortex (BA 17), and lingual (BA 19) and middle occipital gyri (BA 18/19) of the right hemisphere. The third presentation resulted in increased rCBF in the lingual (BA 19), and parahippocampal gyri (BA 35) of the right hemisphere, the thalamus and amygdala of the left hemisphere, and the hippocampal region bilaterally. The fourth presentation resulted in increased $\mathrm{rCBF}$ in the medial frontal gyrus (BA 8/9) of the right hemisphere, the superior temporal gyrus (BA 39) of the left hemisphere, and the hippocampal region bilaterally. rCBF changes in several regions of interest are shown in Fig. 3. 
A.
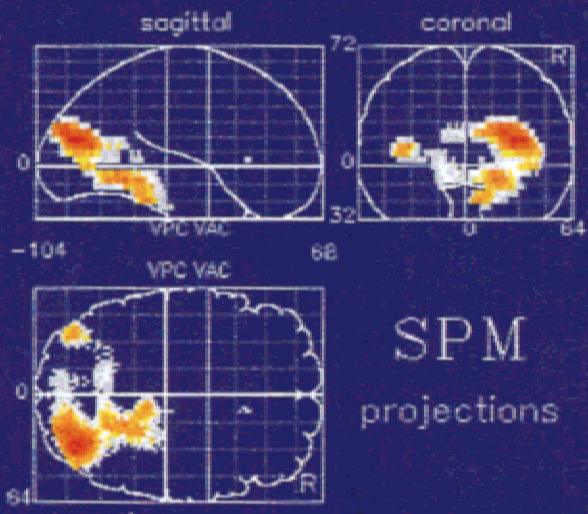

transverse

\section{SPM}

projections
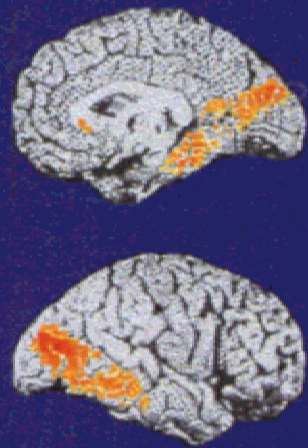

RIGHT
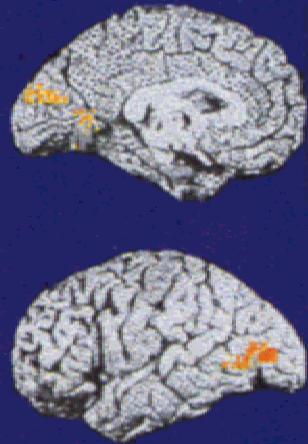

LEFT
B.
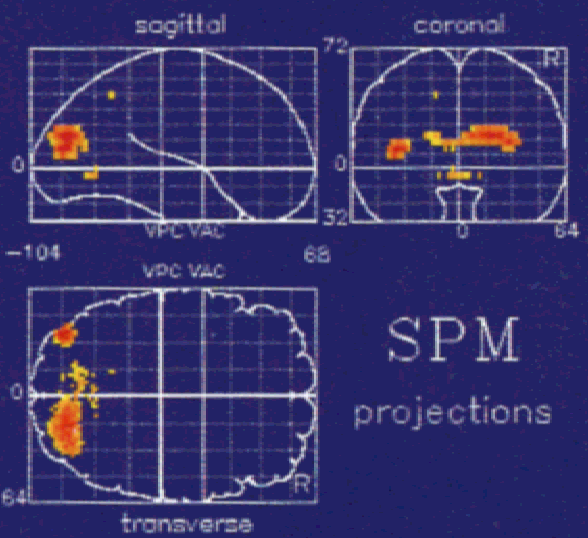

\section{SPM}

projections
D.

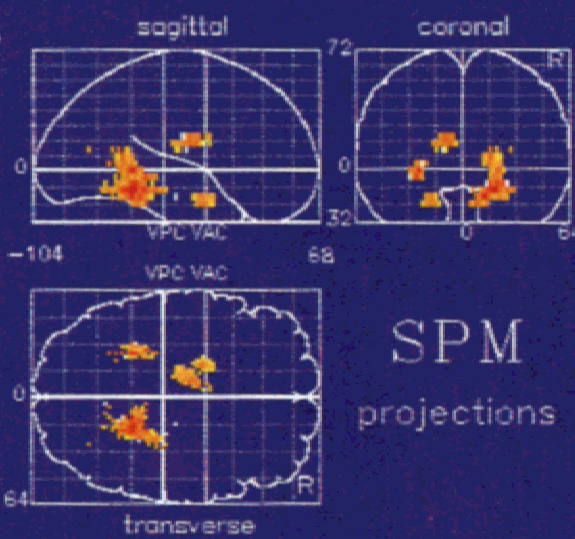

C.

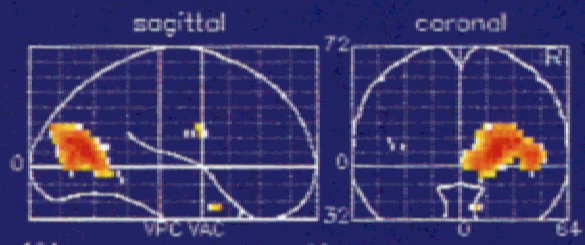

$$
-104
$$

WPC YAC
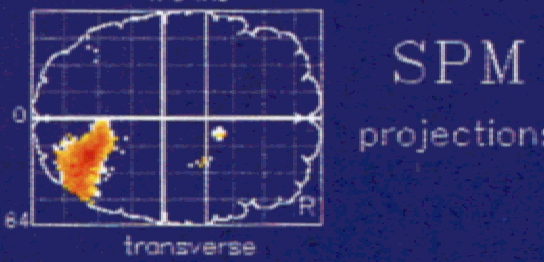

projections
E.

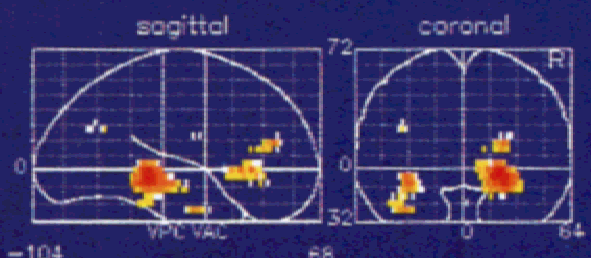

68

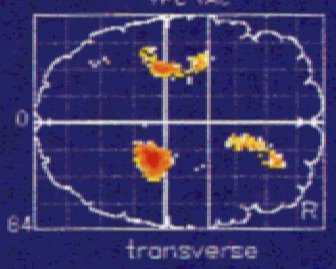

QP $\mid 1$

projections

Fig. 2. Projection maps illustrating significant differences in $\mathrm{rCBF}$ during Even texture perception relative to Random texture perception ( $Z$-score threshold 2.36; spatial extent $P \leq 0.05$ ). (A) Overall rCBF increases during Even relative to Random perception. Significant activation is mapped onto projection images (left) and cortical surface templates (right). Cortical templates show medial (top) and lateral (bottom) views of each hemisphere. (B) Activation during the first Even relative to the first Random presentation. (C) Activation during the second Even relative to the second Random presentation. (D) Activation during the third Even relative to the third Random presentation. (E) Activation during the fourth Even relative to the fourth Random presentation. 
Table 1. Local maxima within clusters demonstrating significant increases in $r C B F$ during Even texture stimulation ${ }^{a}$

\begin{tabular}{|c|c|c|c|c|c|}
\hline \multirow[b]{2}{*}{ Condition } & \multirow[b]{2}{*}{ Region } & \multicolumn{3}{|c|}{ Talairach coordinate } & \multirow[b]{2}{*}{ Z-Score } \\
\hline & & $x$ & $y$ & $z$ & \\
\hline Overall & $\begin{array}{l}\text { Striate cortex (17) } \\
\text { Mid occipital gyrus (18) } \\
\text { Mid occipital gyrus (18) } \\
\text { Fusiform gyrus (19) } \\
\text { Lingual gyrus (19) } \\
\text { Parahippocampal gyrus (35) } \\
\text { Brain stem }\end{array}$ & $\begin{array}{r}-8 \\
34 \\
-34 \\
-12 \\
18 \\
24 \\
8\end{array}$ & $\begin{array}{l}-70 \\
-76 \\
-82 \\
-60 \\
-48 \\
-38 \\
-36\end{array}$ & $\begin{array}{r}16 \\
16 \\
12 \\
-4 \\
-8 \\
-8 \\
-20\end{array}$ & $\begin{array}{l}2.51 \\
4.28 \\
3.35 \\
2.85 \\
3.68 \\
3.45 \\
3.45\end{array}$ \\
\hline First Even scan & $\begin{array}{l}\text { Striate cortex (17) } \\
\text { Striate cortex (17) } \\
\text { Mid occipital gyrus (18) } \\
\text { Mid occipital gyrus (19) } \\
\text { Lingual gyrus (18) } \\
\text { Lingual gyrus (18) }\end{array}$ & $\begin{array}{r}-8 \\
-20 \\
30 \\
-38 \\
2 \\
12\end{array}$ & $\begin{array}{l}-70 \\
-74 \\
-80 \\
-84 \\
-66 \\
-62\end{array}$ & $\begin{array}{r}16 \\
20 \\
16 \\
12 \\
-4 \\
-4\end{array}$ & $\begin{array}{l}2.69 \\
2.43 \\
3.26 \\
3.27 \\
2.55 \\
2.40\end{array}$ \\
\hline Second Even scan & $\begin{array}{l}\text { Striate cortex (17) } \\
\text { Striate cortex (17) } \\
\text { Mid occipital gyrus (19) } \\
\text { Mid occipital gyrus (19) }\end{array}$ & $\begin{array}{r}20 \\
-34 \\
34 \\
44\end{array}$ & $\begin{array}{l}-68 \\
-64 \\
-76 \\
-76\end{array}$ & $\begin{array}{r}12 \\
12 \\
16 \\
8\end{array}$ & $\begin{array}{l}3.56 \\
2.44 \\
3.59 \\
3.38\end{array}$ \\
\hline Third Even scan & $\begin{array}{l}\text { Parahippocampal gyrus (35) } \\
\text { Parahippocampal gyrus (35) } \\
\text { Amygdala } \\
\text { Thalamus }\end{array}$ & $\begin{array}{r}-26 \\
17 \\
-20 \\
-10\end{array}$ & $\begin{array}{r}-42 \\
-41 \\
2 \\
-8\end{array}$ & $\begin{array}{r}0 \\
-8 \\
-20 \\
20\end{array}$ & $\begin{array}{l}2.92 \\
2.50 \\
2.60 \\
2.70\end{array}$ \\
\hline Fourth Even scan & $\begin{array}{l}\text { Hippocampus } \\
\text { Hippocampus } \\
\text { Sup temporal gyrus (39) } \\
\text { Med prefrontal cortex (9) } \\
\text { Parahippocampal gyrus (36) }\end{array}$ & $\begin{array}{r}24 \\
-26 \\
-36 \\
24 \\
-34\end{array}$ & $\begin{array}{r}-32 \\
-30 \\
-58 \\
42 \\
-6\end{array}$ & $\begin{array}{r}-8 \\
-4 \\
24 \\
16 \\
-24\end{array}$ & $\begin{array}{l}3.58 \\
3.21 \\
2.44 \\
3.12 \\
2.84\end{array}$ \\
\hline
\end{tabular}

${ }^{\text {a} B r o d m a n n ~ a r e a s ~ a r e ~ i n d i c a t e d ~ i n ~ p a r e n t h e s e s ~ f r o m ~ t h e ~ a t l a s ~ o f ~ T a l a i r a c h ~ a n d ~ T o u r n o u x ~(1988) . ~}$

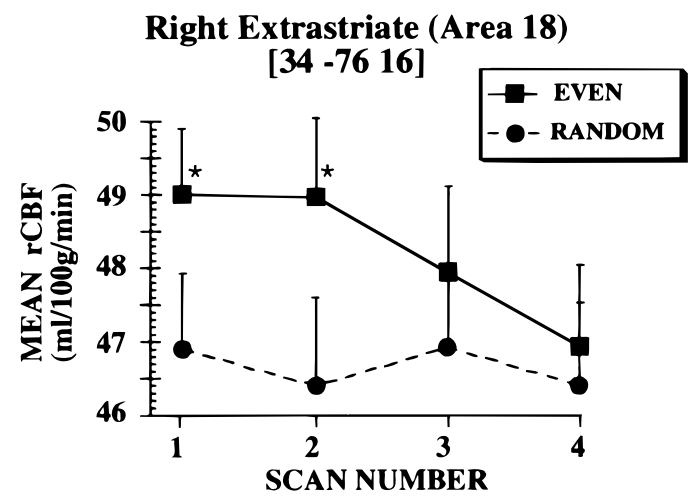

Right Hippocampal Region

$\left[\begin{array}{lll}24 & -32 & -8\end{array}\right]$

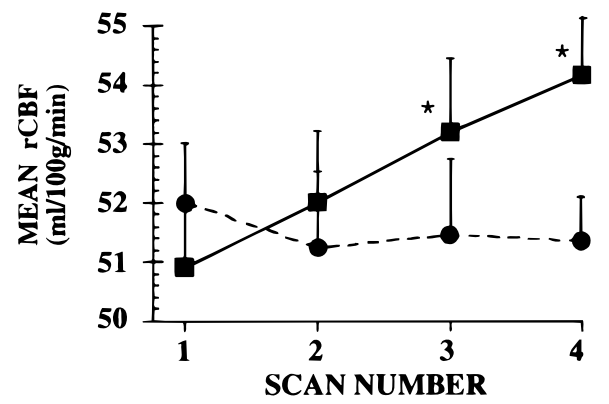

Right Prefrontal (Area 9) [24 42 16]

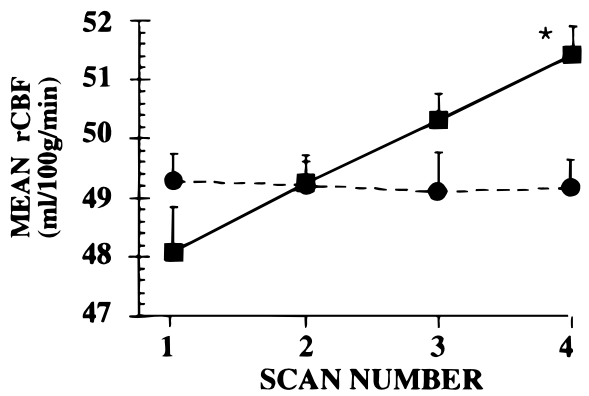

Left Hippocampal Region $[-26-30-4]$

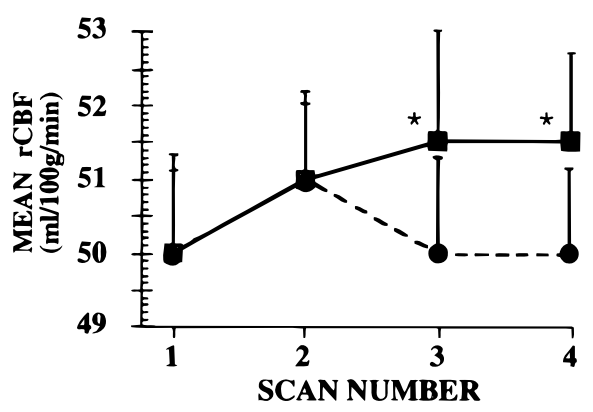

Fig. 3. $\mathrm{rCBF}$ changes over time. Data analyzed with repeated measure ANOVAs for overall within- and between-condition comparisons and post hoc paired sample $t$-tests (two-tailed) for scan specific between-condition comparisons. For all graphs, no significant change in $\mathrm{rCBF}$ was seen over time in the Random condition. In contrast, during the Even condition significant changes in $\mathrm{rCBF}$ were seen over time for all pixel coordinates $(P \leq 0.05)$. Asterisks denote significant between-condition differences $(P \leq 0.05)$. 


\section{Discussion}

The results of this study are threefold. First, the presence of extended contours and rectangular shapes enhanced $\mathrm{rCBF}$ in the occipitotemporal pathway relative to textures lacking these organized features but sharing the same spatial power. Second, this activation appeared to be lateralized predominately to the right hemisphere. Third, on a scan-by-scan basis, activation of occipitotemporal neocortical regions was observed in early scans, while activation of medial temporal and frontal regions was observed in later scans. Thus, there was a forward progression of activation with repeated exposure to Even textures.

By using classes of textures balanced for spatial-frequency content, we have isolated brain regions involved in local feature extraction. Unlike paradigms that confound differences in spatialfrequency content with differences in the organization of local features, the present experimental findings include regions involved exclusively in the analysis of elementary visual form. Here, we have shown that the processing of local features results in activity of visual cortices within both occipital and temporal lobes of the brain, a finding which suggests the presence of similar cortical receptive-field mechanisms throughout the occipitotemporal pathway. Furthermore, the right hemisphere lateralization of this activation is consistent with the visual nature of letters and false fonts (Peterson et al., 1990) and other imaging studies examining perceptual grouping and local feature detection in humans (Hirsch et al., 1995; Fink et al., 1997).

Victor and Conte (1991) have shown that the most plausible model for Even/Random texture discrimination involves two stages of processing: simple edge detection that operates locally, followed by a stage of integration that cooperatively links the outputs of neighboring local edge detectors sharing a common orientation preference. Grossberg et al. (1997) propose a similar model taking into account the cell types, cortical laminae, and flow of information through the cortex that may produce such a computation. Single-unit, local-field potential and epicortical recordings in the monkey indicate that such a mechanism may be present in areas V1, V2, and V3 (Purpura et al., 1993, 1994; Victor \& Purpura, 1996, 1997). While PET can reveal areas of the brain which respond to a given stimulus, it is not possible to determine specific receptive-field mechanisms which result in the regional activation. However, the occipitotemporal activation shown in the present study suggests the participation of the ventral pathway in local feature integration related to the processing of Even textures. It may be that a mechanism such as the one proposed by Victor and Conte (1991) is responsible for the activation observed here.

The unusual aspect of the present study, however, is that activation along the length of the ventral pathway was exposure dependent. With increased viewing of these textures, the activation pattern progressively shifted from posterior to more anterior regions. Neuroimaging studies have shown that repeated visual presentations of word stems (e.g. the first three letters of a word) result in decreased $\mathrm{rCBF}$ in the occipital lobe, specifically striate cortex in the left hemisphere and extrastriate cortices in the right hemisphere (Buckner et al., 1995; Badgaiyan \& Posner, 1996; Blaxton et al., 1996). It is thought that shape characteristics of the letters which make up the word stems lead to "form-specific" priming. That is, repeated presentations of these stimuli result in increased efficiency in perceptual processing and therefore decreases in neuronal activity (Marsolek et al., 1992). While no significant change in occipital $\mathrm{rCBF}$ was seen during stimulation with textures lacking local features or form elements, decreased
rCBF during Even texture stimulation is consistent with the hypothesis of form-specific priming.

The forward progression of increased $\mathrm{rCBF}$ beyond occipital and temporal visual cortices is more difficult to explain. This finding suggests that some aspect of the Even textures stimulates activity in the medial temporal and frontal lobes with repeated viewing. It is known that damage limited to the hippocampus or prefrontal cortex disrupts the ability to recognize or remember specific stimuli (Mahut et al., 1982; Milner et al., 1985; Zola-Morgan et al., 1986; Bachevalier \& Mishkin, 1986). PET studies have also shown activation of the hippocampus (Grady et al., 1995; Roland \& Gulyas, 1995; Schacter et al., 1996) and prefrontal cortex (Squire et al., 1992; Buckner et al., 1995; Cabeza et al., 1997) during encoding and retrieval of visual information. In the present study, it may be that activation of hippocampal and prefrontal regions occurs because the local features within Even textures become more meaningful or recognizable with repeated viewing. Based on psychophysical studies of visual perception, this activity may also reflect processes related to the categorization of visual information (Posner \& Keele, 1968; Medlin \& Schaffer, 1978) as a function of stimulus familiarity. Because of the passive nature of the paradigm, however, the exact cause of this anterior activation remains unclear.

Overall, this study demonstrates that viewing visual textures composed of local features results in activation of the occipitotemporal pathway in humans. This finding illustrates that the ventral visual pathway is involved in elementary form perception and suggests the presence of similar processing capabilities, perhaps similar receptive-field mechanisms, in both occipital and temporal neocortical visual areas. Because of the regional activity elicited by this task and the noncompliant or passive nature of the design, future studies of this type may be of value in probing neocortical and hippocampal function in cognitively impaired subjects who are unable to perform more complex brain activation paradigms.

\section{Acknowledgments}

We thank Dr. D.L. Longo for helpful manuscript suggestions and Dr. J.Ma. Maisog for assistance and software programs used in data analysis. K.P. Purpura was supported by Grant NS-01677.

\section{References}

BacheVAlier, J. \& Mishkin, M. (1986). Visual recognition impairment follows ventromedial but not dorsolateral prefrontal lesions in monkeys. Behavioral Brain Research 20, 249-261.

Badgaiyan, R. \& Posner, M. (1996). Priming reduces input activity in right posterior cortex during stem completion. NeuroReport 7, 29752978.

Baizer, J.S., Ungerleider, L.G. \& Desimone, R. (1991). Organization of visual inputs to the inferior temporal and posterior parietal cortex in macaques. Journal of Neuroscience 11, 168-190.

Blaxton, T.A., Bookheimer, S.Y., ZefFiro, T.A., Figlozzi, C.M., GaIlLARD, W.D. \& THEOdORE, W.H. (1996). Functional mapping of human memory using PET: Comparisons of conceptual and perceptual tasks. Canadian Journal of Experimental Psychology 50, 42-56.

Buckner, R.L., Petersen, S.E., Ojemann, J.G., Miezin, F.M., Squire, L.R. \& RaICHLE, M.E. (1995). Functional anatomical studies of explicit and implicit memory retrieval tasks. Journal of Neuroscience 15, 12-29.

Cabeza, R., Grady, C.L., Nyberg, L., McIntosh, A.R., Tulving, E., Kapur, S., Jennings, J.M., Houle, S. \& Craik, F.I. (1997). Agerelated differences in neural activity during memory encoding and retrieval: A positron emission tomography study. Journal of Neuroscience 17, 391-400.

Carson, R.E., Berg, G.W., Finn, R.D., Patlak, C.S., DaubeWitherspoon, M.E., Stien, S.D., Simpson, N.R., Green, M.V. \& 
LARSON, S.M. (1987). Tomographic measurement of rCBF with highresolution PET and $\mathrm{H}_{2}{ }^{15} \mathrm{O}$ : Comparison of methods. Journal of Cerebral Blood Flow \& Metabolism 7, S578.

Corbetta, M., Miezin, F.M., Dobmeyer, S., Shulman, G.L. \& PeterSON, S.E. (1990). Attentional modulation of neural processing of shape, color, and velocity in humans. Science 248, 1556-1559.

Desimone, R. \& Duncan, J. (1995). Neural mechanisms of selective visual attention. In Annual Review of Neuroscience, ed. Cowan, W., pp. 193-222. Palo Alto, California: Annual Reviews Inc.

Doyon, J. \& Milner, B. (1991). Role of the right temporal lobe in visualcue learning during repeated pattern discriminations. Neuropsychologia 29, 861-876.

Fink, G., Marshall, J., Halligan, P., Frith, C., Frackowiak, R. \& Dolan, R. (1997). Hemispheric specialization for global and local processing: The effect of stimulus category. Proceedings of the Royal Society $B$ (London) 264, 487-494.

Fox, P.T., Mintun, M.A., Reiman, E.M. \& Raichle, M.E. (1988). Enhanced detection of focal brain responses using intersubject averaging and change-distribution analysis of subtracted PET images. Journal of Cerebral Blood Flow and Metabolism 8, 642-653.

FrackowiaK, R.S. \& Friston, K.J. (1994). Functional neuroanatomy of the human brain: Positron emission tomography-a new neuroanatomical technique. Journal of Anatomy 184, 211-225.

Friston, K.J., Frith, C.D., Liddle, P.F. \& Frackowiak, R.S.J. (1991). Plastic transformation of PET images. Journal of Computer Assisted Tomography 15, 634-639.

Friston, K.J., Worsley, K.J., Frackowiak, R.S.J., Mazziotta, J.C. \& Evans, A.C. (1994). Assessing the significance of focal activations using their spatial extent. Human Brain Mapping 1, 210-220.

GafFAn, D., HARrison, S. \& GaFfan, E.A. (1986). Visual identification following inferiotemporal ablation in the monkey. Quarterly Journal of Experimental Psychology 38, 5-30.

Gattass, R., Sousa, A. \& Gross, C. (1988). Visuotopic organization and extent of V3 and V4 of the macaque. Journal of Neuroscience $\mathbf{8}$, 1831-1845.

Grady, C.L., McIntosh, A.R., Horwitz, B., Maisog, J.M., UngerLeider, L.G., Mentis, M.J., Pietrini, P., Schapiro, M.B. \& Haxby, J.V. (1995). Age-related reductions in human recognition memory due to impaired encoding. Science $\mathbf{2 6 9}, 218-221$.

Grossberg, S., Mingolla, E. \& Ross, W.D. (1997). Visual brain and visual perception: How does the cortex do perceptual grouping? Trends in Neuroscience 20, 106-111.

Gur, R., Ragland, J., Mozley, L., Smith, R., Alavi, A., Bilker, W. \& GUR, R. (1997). Lateralized changes in regional cerebral blood flow during performance of verbal and facial recognition tasks: Correlations with performance and effort. Brain and Cognition 33, 388-414.

Haxby, J.V., Grady, C.L., Horwitz, B., Ungerleider, L.G., MishKin, M., Carson, R.E., Herscovitch, P., Schapiro, M.B. \& Rapoport, S.I. (1991). Dissociation of object and spatial visual processing pathways in human extrastriate cortex. Proceedings of the National Academy of Sciences of the U.S.A. 88, 1621-1625.

Hirsch, J., Delapaz, R.L., Relkin, N.R., Victor, J., Kim, K., Li, T., Borden, P., Rubin, N. \& Shapley, R. (1995). Illusory contours activate specific regions in human visual cortex: Evidence from functional magnetic resonance imaging. Proceedings of the National Academy of Sciences of the U.S.A. 92, 6469-6473.

Holden, J.E., Gatley, S.J., Hichwa, R.D., Ip, W.R., Shaughnessy, W.J., NiCKLES, R.J. \& PolyCN, R.E. (1981). Cerebral blood flow using PET measurements of fluoromethane kinetics. Journal of Nuclear Medicine 22, 1084-1088

Horwitz, B., Grady, C.L., Haxby, J.V., Schapiro, M.B. \& Rapoport, S.I. (1992). Functional associations among human posterior extrastriate brain regions during object and spatial vision. Journal of Cognitive Neuroscience 4, 311-322.

Jueptner, M. \& Weiller, C. (1995). Does measurement of regional cerebral blood flow reflect synaptic activity? Implications for PET and fMRI. NeuroImage 2, 148-156.

Julesz, B., Gilbert, E.N. \& ViCTOR, J.D. (1978). Visual discrimination of textures with identical third-order statistics. Biological Cybernetics 31, 137-140.

Kapur, S., Tulving, E., Cabeza, R., Mcintosh, A., Houle, S. \& Craik, F. (1996). The neural correlates of intentional learning of verbal materials: A PET study in humans. Cognitive Brain Research 4, 243-249.

KLEIST, K. (1934). Gehirnpathologie. Barth: Liepzig.

Kosslyn, S.M., Alpert, N.M., Thompson, W.L., Chabris, C.F., Rauch,
S.L. \& ANDERSON, A.K. (1994). Identifying objects seen from different viewpoints, a PET investigation. Brain 117, 1055-1071.

Logothetis, N., Pauls, J. \& Poggio, T. (1995). Shape representation in the inferior temporal cortex of monkeys. Current Biology 5, 552-563.

Logothetis, N. \& Sheinberg, D. (1996). Visual object recognition. In Annual Review of Neuroscience, ed. Cowan, W., pp. 577-621. Palo Alto, California: Annual Reviews, Inc.

Luck, S., Chelazzi, L., Hillyard, S. \& Desimone, R. (1997). Neural mechanisms of spatial selective attention in areas V1, V2, and V4 of macaque visual cortex. Journal of Neurophysiology 77, 24-42.

Mahut, H., Zola-Morgan, S. \& Moss, M. (1982). Hippocampal resections impair associative learning and recognition memory in the monkey. Journal of Neuroscience 2, 1214-1229.

Malach, R., Reppas, J.B., Benson, R.R., Kwong, K.K., Jiang, H., KenNedy, W.A., Ledden, P.J., Brady, T.J., B.R., R. \& Tootell, R.B.H. (1995). Object-related activity revealed by functional magnetic resonance imaging in the human occipital cortex. Proceedings of the $\mathrm{Na}$ tional Academy of Sciences of the U.S.A. 92, 8135-8139.

MarsoleK, C.J., Kosslyn, S.M. \& SQuire, L.R. (1992). Form-specific visual priming in the right cerebral hemisphere. Journal of Experimental Psychology 18, 492-508.

Medlin, D.L. \& Schaffer, M.M. (1978). Context theory of classification learning. Psychological Review 85, 207-238.

Menard, M., Kosslyn, S., Thompson, W., Alpert, N. \& Rauch, S. (1996). Encoding of words and pictures: A positron emission tomography study. Neuropsychologia 34, 185-194.

Milner, B., Petrides, M. \& Smith, M.L. (1985). Frontal lobes and the temporal organization of memory. Human Neurobiology 4, 137-142.

MotTer, B. (1993). Focal attention produces spatially selective processing in visual cortical areas V1, V2, and V4 in the presence of competing stimuli. Journal of Neurophysiology 70, 909-919.

Petersen, S.E., Fox, P.T., Snyder, A.Z. \& Raichle, M.E. (1990). Activation of extrastriate and frontal cortical areas by visual words and word-like stimuli. Science 249, 1041-1044.

Pigott, S. \& Milner, B. (1993). Memory for different aspects of complex visual scenes after unilateral temporal- or frontal-lobe resection. Neuropsychologia 31, 1-15.

Posner, M.I. \& Keele, S.W. (1968). On the genesis of abstract ideas Journal of Experimental Psychology 77, 353-363.

Posner, M.I. \& RAichle, M.E. (1994). Images of the brain. In Images of Mind: Exploring the Brain's Activity, pp. 53-82. New York, New York: Scientific American Library.

Puce, A., Allison, T., Asgari, M., Gore, J.C. \& McCarthy, G. (1996) Differential sensitivity of human visual cortex to faces, letterstrings and textures: A functional magnetic resonance study. Journal of Neuroscience 16, 5205-5215.

Puce, A., Allison, T., Gore, J.C. \& McCarthy, G. (1995). Face-sensitive regions in human extrastriate cortex studied by functional MRI. Journal of Neurophysiology 74, 1192-1199.

Purpura, K., Chee-Orts, M. \& Optican, L. (1993). Temporal encoding of texture properties in visual cortex of awake monkey. Society for Neuroscience Abstracts 19, 771.

Purpura, K.P., Victor, J.D. \& Katz, E. (1994). Striate cortex extracts higher-order spatial correlations from visual textures. Proceedings of the National Academy of Sciences of the U.S.A. 91, 8482-8486.

Roland, P.E. \& Gulyas, B. (1995). Visual memory, visual imagery, and visual recognition of large field patterns by the human brain: Functional anatomy by positron emission tomography. Cerebral Cortex 1, 79-93.

Schacter, D.L., Rieman, E., Uecker, A., Polster, M.R., Yun, L.S. \& Cooper, L.A. (1995). Brain regions associated with retrieval of structurally coherent visual information. Nature 376, 587-590.

Schacter, D.L., Savage, C.R., Alpert, N.M., Rauch, S.L. \& Albert, M.S. (1996). The role of the hippocampus and frontal cortex in agerelated memory changes: A PET study. NeuroReport 7, 1165-1169.

Souire, L.R., Ojemann, J.G., Miezin, F.M., Peterson, S.E., Videen, T.O. \& RAICHLE, M.E. (1992). Activation of the hippocampus in normal humans: A functional anatomical study of memory. Proceedings of the National Academy of Sciences of the U.S.A. 89, 1837-1841.

SuzUKI, W. (1996). The anatomy, physiology and functions of the perirhinal cortex. Current Opinions in Neurobiology 6, 179-186.

Talairach, J. \& Tournoux, P. (1988). Co-Planar Stereotaxic Atlas of the Human Brain. New York: Thieme Medical Publishers, Inc.

Ungerleider, L.G. \& Mishkin, M. (1982). Two cortical visual systems. In Analysis of Visual Behavior, ed. Ingle, D.J., Goodale, M.A. \& Mansfield, R.J.W., pp. 549-586. Cambridge, Massachusetts: MIT Press. 
ViCTOR, J.D. (1985). Complex visual textures as a tool for studying the VEP. Vision Research 25, 1811-1827.

VICTOR, J.D. \& ConTE, M.M. (1991). Spatial organization of nonlinear interactions in form perception. Vision Research 31, 1457-1488.

ViCTOR, J.D. \& PURPURA, K.P. (1996). Nature and precision of temporal coding in visual cortex: A metric-space analysis. Journal of Neurophysiology 76, 1310-1326.

Victor, J.D. \& PurPura, K.P. (1997). Metric-space analysis of spike trains: Theory, algorithms, and application. Networks 8, 127-164.

VICTOR, J.D. \& ZEMON, V. (1985). The human visual evoked potential: Analysis of components due to elementary and complex aspects of form. Vision Research 25, 1829-1842.
Woods, R.P., Cherry, S.R. \& MazziontTA, J.C. (1992). Rapid automated algorithm for aligning and reslicing PET images. Journal of Computer Assisted Tomography 16, 620-633.

Wurtz, R. \& Mohler, C. (1976). Enhancement of visual responses in monkey striate cortex and frontal eye fields. Journal of Neurophysiology 39, 766-772.

Zola-Morgan, S., Squire, L.R. \& Amaral, D. (1986). Human amnesia and the medial temporal region: Enduring memory impairment following a bilateral lesion limited to the CA1 field of the hippocampus. Journal of Neuroscience 6, 2950-2967. 